\title{
Esquizofrenia: dando voz à mãe cuidadora'
}

\author{
Schizophrenia: listening to carer mothers
}

\author{
Gisele da SILVA ${ }^{2}$ \\ Manoel Antônio dos SANTOS ${ }^{3}$
}

\begin{abstract}
Resumo
Objetivou-se investigar as repercussões desencadeadas na vida de mães cuidadoras ao longo do curso do transtorno esquizofrênico de seus filhos. Doze participantes responderam a uma entrevista semiestruturada e suas narrativas foram examinadas por meio da análise de conteúdo temática. Foram encontrados sete eixos temáticos, cada qual apontando momentos, problemáticas e correlatos emocionais específicos: estranhamento, o estigma da loucura, a chegada ao consultório médico, o diagnóstico, resistindo ao tratamento médico, mudanças na vida, aceitação ou resignação. Os resultados evidenciaram a natureza invasiva do transtorno mental na vida da mãe cuidadora, a especificidade das sobrecargas vivenciadas em cada período do curso da esquizofrenia e a dificuldade encontrada na elaboração psíquica da condição do filho, mesmo após muitos anos do diagnóstico.
\end{abstract}

Unitermos: Cuidadores. Esquizofrenia. Família. Mães.

\begin{abstract}
This paper aims to investigate the impact on the lives of carer mothers of a son or daughter with a schizophrenic disorder. Twelve participants were questioned in a semi-structured interview, and their stories were reviewed by means of an analysis of the thematic content. The data showed seven themes relating to different moments, each one with specific demands and emotional responses: alienation; the stigma of mental disorder; seeking psychiatric help; diagnosis; resisting medical treatment; life changes; acceptance or resignation. The findings showed the following: Living with a chronic mental disorder, for the participants of this study, was associated with a severe disruption in their lives; the burden of care was different at different moments of the course of the schizophrenia; the emotional acceptance of the son's or daughter's situation was very hard, even many years after diagnosis.
\end{abstract}

Uniterms: Carers. Schizophrenia. Family. Mothers.

A esquizofrenia, enquanto condição crônica e potencialmente incapacitante, traz repercussões não somente ao indivíduo acometido, mas a toda a sua família.

A partir do evento da desinstitucionalização, os cuidados ao doente mental voltaram a ser responsabilidade da família. No entanto, a mudança para- digmática não ocorreu em paralelo a uma reorganização do modelo de assistência em saúde mental. Com isso, os cuidadores veem-se despreparados para desempenhar as funções que Ihes cabem e, ainda, estão pouco amparados pela rede de saúde. Tal quadro tem levado a um aumento, nas últimas décadas, do número de pesquisas que buscam conhecer o impacto do

$\boldsymbol{\nabla \nabla \nabla \nabla}$

1 Pesquisa subvencionada pela Fundação de Amparo à Pesquisa do Estado de São Paulo (Processo no 2000/14905-5).

2 Anhanguera Educacional, Faculdade Politécnica de Jundiaí, Curso de Graduação em Psicologia. R. do Retiro, 3000, 13209-002, Jundiaí, SP, Brasil. Correspondência para/Correspondence to: G. SILVA.E-mail:<gisele95@yahoo.com>.

3 Universidade de São Paulo, Faculdade de Filosofia, Ciências e Letras de Ribeirão Preto, Departamento de Psicologia e Educação, Ribeirão Preto. 
transtorno mental na família, objetivando a obtenção de conhecimento para o atendimento das novas necessidades dessa clientela.

Os estudos com foco nos cuidadores têm destacado, entre os temas recorrentes, alguns aspectos relacionados à sobrecarga nos cuidados ao doente mental: a convivência com uma realidade que não conhecem, o estigma social que acompanha os transtornos psiquiátricos, a imprevisibilidade do paciente, a modificação da rotina e dos papéis sociais, a alteração nas relações familiares e a falta de suporte social percebido (Brady \& McCain, 2004; Saunders \& Byrne, 2002).

As pesquisas com cuidadores invariavelmente enfatizam o alto nível de sobrecarga gerado pelo convívio com o doente mental (Saunders, 2003; Teschinsky, 2000). As variações encontradas no nível de sobrecarga sentido pelo familiar são mediadas tanto por fatores objetivos como subjetivos (Koukia \& Madianos, 2005; Moller-Leimkuhler, 2005; Rosenfarb, Bellack \& Aziz, 2006). Incluem-se nas sobrecargas objetivas fatores como a gravidade dos sintomas, o subtipo do diagnóstico e o número de horas de convívio direto com o paciente. Já entre os fatores que encerram sobrecarga subjetiva estão, por exemplo, as respostas de enfrentamento, o nível de stress e o suporte social.

O alto nível de sobrecarga familiar está relacionado à diminuição da qualidade de vida (Foldemo, Gullberg, Ek \& Bogren, 2005; Gutierrez-Maldonado, Caqueo-Urizar \& Kavanagh, 2005) e ao surgimento de transtornos psiquiátricos no seio familiar. Laidlaw, Coverdale, Fallon e Kydd (2002) investigaram famílias inglesas de portadores de esquizofrenia e encontraram que 25\% dos cuidadores apresentavam algum transtorno mental.

Considerando que os familiares estão mergulhados em sobrecargas de cuidados, alguns trabalhos têm se preocupado em investigar as necessidades que eles apresentam. Os resultados têm apontado para carências que se expressam em diversos níveis: de informações sobre a doença e seu tratamento; de identificação de recursos de saúde, sociais e legais; e de ajuda psicológica no enfrentamento da problemática (Pollio, North, Reid, Miletic \& McClendon, 2006).

É consenso na literatura científica a importância atribuída ao desenvolvimento de intervenções junto a essa população. As estratégias já desenvolvidas nesse sentido são multifacetadas, podendo encerrar abordagens informativas, de apoio ou psicoterápica. Independentemente do caráter da intervenção, as avaliações de tais trabalhos demonstraram a obtenção de benefícios nos relacionamentos familiares, diminuição da sobrecarga e melhora na saúde do cuidador (Bradley et al., 2006; Cheng \& Chan, 2005; Koukia \& Madianos, 2005). Há, no entanto, uma baixa adesão dos familiares às intervenções realizadas nos serviços de saúde.

Apesar do significativo número de pesquisas voltadas ao tema do cuidador de indivíduos acometidos por esquizofrenia, há uma escassez de publicações que investiguem se as sobrecargas vivenciadas ao longo do curso da doença são similares ou se alteram. Seriam as dificuldades de uma família que está passando pelo período do diagnóstico, por exemplo, as mesmas de outra que convive com a falta de autonomia de um filho doente há mais de uma década? A despeito da importância de tal conhecimento para os profissionais que intervêm junto a esta clientela, observa-se, na literatura, uma lacuna na busca de respostas para essa questão.

Tendo em vista essas premissas, o objetivo deste trabalho foi investigar as repercussões, ao longo do tempo, da convivência com um filho portador de esquizofrenia, na perspectiva de mães cuidadoras. Mais especificamente, objetivou-se traçar um panorama do percurso das vivências da mãe com o transtorno esquizofrênico do filho, buscando distinguir os períodos vivenciados no que diz respeito às sobrecargas e necessidades engendradas em cada momento.

\section{Método}

O trabalho, norteado pelas diretrizes da Resolução no 196/96 do Conselho Nacional de Saúde, que regulamenta as pesquisas envolvendo seres humanos, foi encaminhado e aprovado pelo Comitê de Ética em Pesquisa da Faculdade de Filosofia, Ciências e Letras de Ribeirão Preto da Universidade de São Paulo (protocolo n॰02/2000 - 2000.1.871.59.3).

\section{Participantes}

Participaram da pesquisa 12 mães de portadores de esquizofrenia, contatadas a partir dos prontuários 
do Centro de Atenção Psicossocial (CAPS) de Ribeirão Preto. A seleção das participantes, portanto, foi intencional; foram entrevistadas aquelas mães que consentiram em colaborar com o estudo e que preenchiam os seguintes critérios: 1) tempo mínimo de cinco anos desde o diagnóstico do filho; 2) responsabilidade direta pela maior parte dos cuidados dispensados ao filho.

A idade das mães variou entre 43 e 74 anos (média de 58,8 anos). Em relação ao estado civil, quatro mães estavam viúvas, quatro eram separadas e quatro casadas. O número de filhos variou entre dois e 12; apenas três mães tiveram menos que quatro filhos. Com relação ao sexo do filho portador de esquizofrenia, apenas quatro eram mulheres. O tempo de convivência com o transtorno mental esquizofrênico variou entre cinco e trinta anos (média de 14,9 anos).

Com referência à atividade profissional, apenas duas participantes exerciam atividade remunerada na ocasião da coleta de dados. Os anos de escolaridade das mães variaram de nenhum a 16 (média de 6,9 anos). Quanto à religiosidade, seis mães declararam-se católicas, três evangélicas, duas espíritas e uma budista.

\section{Instrumentos}

Utilizou-se um roteiro de entrevista semiestruturado, elaborado especialmente para a investigação em questão. Nesse instrumento, as questões objetivaram, primeiramente, a caracterização sociodemográfica da participante e, em seguida, a reconstrução de todo o percurso de convivência com o transtorno mental do filho, desde as primeiras alterações comportamentais percebidas até os momentos atuais.

\section{Procedimentos}

O procedimento de coleta de dados foi aplicado individualmente, em situação face a face, em sala reservada do Centro de Atenção Psicossocial ou na residência das participantes, com condições adequadas de privacidade.

No momento que precedeu à coleta de dados entregou-se uma via do Termo de Consentimento Livre e Esclarecido, que a entrevistada e a pesquisadora leram e assinaram. Nesse documento ressaltava-se o aspecto sigiloso e voluntário da participação, esclarecendo que a não participação ou eventual desistência não acarretaria qualquer ônus ou prejuízo à participante.

Todas as entrevistas foram audiogravadas após obtenção do consentimento das participantes. O material coletado foi transcrito na íntegra e literalmente a partir dos registros em áudio. Os depoimentos foram submetidos a uma análise de conteúdo temática (Minayo, 2000). São três as etapas desse processo de análise: 1) pré-análise, que consiste na organização do material e sistematização das ideias contidas nos relatos; 2) descrição analítica, que corresponde à categorização dos dados em unidades de registros; 3 ) interpretação referencial, que se relaciona ao tratamento e interpretação dos dados.

\section{Resultados e Discussão}

As mães que participaram deste estudo conviviam com um filho que, nos primeiros estágios do desenvolvimento, era percebido como saudável. Alimentaram sonhos e construíram planos para seu futuro. No entanto, com o chegar da adolescência, alterações nos padrões comportamentais e emocionais do rebento invadiram a vida familiar. Com isso, ao invés da concretização das expectativas idealizadas nos primeiros anos de vida, os projetos precisaram ser interrompidos. A atenção familiar mudou de direção e o fluxo de energia vital dessas mães precisou ser reorientado.

As narrativas colhidas mediante a aplicação da entrevista trouxeram à tona o percurso que se deu a partir de então, com discursos frequentemente acompanhados de expressões emocionais que evidenciaram a intensidade das angústias que os acontecimentos evocados continham - e ainda contêm - em suas vidas.

Foram encontrados sete eixos temáticos, cada qual apontando momentos, problemáticas e correlatos emocionais específicos: estranhamento, o estigma da loucura, a chegada ao consultório médico, o diagnóstico, resistindo ao tratamento médico, mudanças na vida, aceitação ou resignação.

\section{Estranhamento: enfrentando a falta de sentido}

Dentre as lembranças acerca das primeiras alterações percebidas nos filhos, as mães relataram com 
maior frequência: rompantes de agressividade, isolamento, mudanças de hábitos e abandono de projetos:

Ele não saía mais do quarto, não conversava com ninguém. Só lia livros de química. O tempo todo, só isso (mãe 6).

Foi muito de repente, ficou agressiva (mãe 8).

Tinha umas atitudes estranhas. Pulava do carro, via gente. Tinha medo de tudo. Não queria nem saber de tomar banho (mãe 5).

Os relatos sobre as diferenças notadas no filho evidenciaram o vasto rol de possibilidades sintomáticas que culminaram na quebra da homeostase familiar. Apesar da singularidade da experiência de cada família, esse período foi acompanhado, segundo todos os relatos, de uma ideia recorrente: algo estava fora do lugar, da ordem familiar; algo estranho estava acontecendo. Algo que não podia ser explicado pelos esquemas habituais de compreensão utilizados pela família, pois desviava do sistema explicativo. Algo para o qual não se tinha um código, um discurso, um símbolo que ordenasse o entendimento do que estava se passando.

Estranhamento é a denominação conferida, neste estudo, ao estado de alerta que as mães participantes relataram ter vivido nesse período inicial. Percebiam que algo estava ocorrendo, porém não sabiam nomear ou entender totalmente a situação. Tratavam-se apenas de ideias vagas, que não estavam fundamentadas ou que não constituíam uma unidade coerente.

Condizente com uma realidade que não compreendiam, todas as mães referiram que, nesse momento, não sabiam que atitude tomar para contornar a situação. A sensação era de que estavam confusas, aturdidas, perdidas diante da aparente ausência de sentido nos comportamentos extravagantes dos filhos: "Eu não entendia nada" (mãe 7); "Ao invés de ajudar, eu ficava desesperada, acho que piorava tudo. Eu não sabia oquefazer" (mãe 10).

A angústia vivenciada nesse período foi descrita como crescente, culminando na efetivação de alguma ação, com objetivo de encontrar uma solução ou vislumbrar uma saída para a problemática viven88 ciada.
O estigma da loucura: o encontro com o indesejável

As mães referiram a necessidade de buscar auxílio tanto para extravasar sentimentos perturbadores quanto para encontrar sentido e procurar soluções para a condição familiar.

A maior parte dos relatos apontou para a utilização de recursos alternativos anteriormente à procura pelo aparato médico-científico. Para essas mães, a busca de apoio na religião, no misticismo, em organizações comunitárias e na medicina alternativa consistiu no primeiro recurso de que lançaram mão. Buscavam compreensão e alívio para a problemática, ainda não esclarecida, que estavam vivenciando.

O recurso médico-científico, na maioria dos casos, tardou a ser procurado. Essa demora, traduzida em tempo de calendário, configurou-se de alguns meses a anos. Por que, no entanto, a medicina demorou a surgir como uma possibilidade para tantas famílias?

As participantes relataram que, no período pré-diagnóstico, faltava-Ihes conhecimento, em maior ou menor grau, acerca dos chamados transtornos mentais. Desconheciam as causas, os tratamentos e as possibilidades do indivíduo acometido por um transtorno psiquiátrico. No entanto, uma inquietação fortemente arraigada em seu imaginário era, segundo seus próprios relatos, o estigma da loucura. $O$ pouco que sabiam sobre transtornos mentais vinha acompanhado de uma forte conotação negativa. Com isso, recoberta pelo preconceito, a possibilidade de estarem diante de um transtorno psiquiátrico provavelmente não era uma hipótese bem-vinda. O acometimento por uma condição crônica e estigmatizante, especialmente quando se trata de um filho, geralmente desperta um sentimento de fracasso nos pais.

Enfim, o desconhecimento acerca da real natureza das perturbações mentais, aliado ao estigma e aos preconceitos historicamente associados à loucura, pode ter constituído uma combinação de fatores que contribuíram para a demora da procura pelo aparato médico-científico como um recurso de apoio e nomeação da experiência vivida.

\section{A chegada ao consultório médico: a busca de um sentido para o sofrimento}

A chegada ao consultório ou ao serviço de saúde mental não implicou que a mãe já estivesse, naquele 
momento, com uma ideia clara do que estava se passando com seu filho. Apesar de um início de conscientização de que podia se tratar de uma doença psíquica, da mente ou "dos nervos", de acordo com suas próprias palavras, a maioria das participantes referiu que o desconhecimento acerca da doença mental ainda persistia na ocasião da consulta inicial.

Nesse momento, a medicina significava a esperança de encontrar uma cura milagrosa. Pode-se dizer que o desejo de que tudo voltasse a ser como antes era imperioso e impunha-se sobre uma possível abertura psíquica para o reconhecimento e enfrentamento de uma realidade indesejada.

\section{O diagnóstico: onde foi que eu errei?}

O que ocorreu quando, em vez de cura, as mães depararam com o diagnóstico de um transtorno mental grave e potencialmente incapacitante?

As mães não raro utilizaram metáforas para ilustrar o modo como vivenciaram esse momento: "Passou uma tempestade aqui na minha casa" (mãe 2); "É como você dormir e acordarno meio de uma guerra.... Écomo se eu tivesse indo pra um caminho e, de repente, tivesse que voltar tudo de novo, começar tudo de novo" (mãe 7).

O período de confirmação do diagnóstico, conforme as recordações das participantes, mostrou, ser uma fase na qual as mães encontravam-se muito fragilizadas, em função da concretização de seus temores. Os relatos mostram que se estabeleceu uma espécie de "tempo de catástrofe", no qual uma gama de sentimentos, inclusive contraditórios, evidenciou um estado de confusão, característico de um momento de crise. De um lado: revolta, medo, fragilidade, impotência, dúvida, perda; de outro: fé, esperança, otimismo, resignação.

Nesse momento surgiram também sentimentos dolorosos de incerteza e dúvida com relação às suas capacidades e à adequação de suas próprias atitudes como mãe, bem como a busca por supostos erros cometidos ao longo do processo educativo do filho. Afinal, será que ela própria não teve influência no aparecimento da doença? Teria sido realmente uma boa mãe? Onde foi que errou na criação do filho? "Cheguei a pensar que faltou amor de mãe" (mãe 7); "No começo eu me culpava, achava que tinha educado errado, que tinha faltado alguma vitamina, não sei..." (mãe 9).

\section{Resistindo ao tratamento médico: eu fazia de conta que não via}

O percurso que se seguiu após o diagnóstico mostrou não ser uma linha reta rumo à aceitação e reorganização frente à nova realidade do filho. As narrativas obtidas evidenciaram, ao contrário, um caminho tortuoso, permeado por idas e vindas. Ao mesmo tempo em que se alcançava um início de conscientização acerca das novas demandas da vida familiar, as mães, implícita ou explicitamente, reportaram o quanto resistiam em aceitar a realidade introduzida pelo transtorno mental do filho.

Indícios de não aceitação da doença do filho foram constatados em diversas posições assumidas frente à problemática. Entre elas, a recusa de que a condição do filho correspondia aos efeitos de um quadro clínico crônico, assumindo, ao invés disso, a postura de que se tratava apenas de descontrole dos nervos: "Eu não via como uma doença. Achava que estava com os nervos descontrolados equeia passar" (mãe 5).

Outros posicionamentos maternos que evidenciaram a dificuldade de aceitação do quadro do filho puderam ser percebidos na dificuldade em aceitar o tratamento medicamentoso ou, ainda, na alta frequência de trocas de profissionais da área médica:

$\mathrm{Na}$ realidade eu não queria que ele tomasse (a medicação), eu tinha medo. E, na realidade, eu acho que ele percebia esse medo e ele também não tomava. Eu acho que ele jogava fora. Eu fazia de conta que não via e... sabe? Eialevando (mãe 9).

Agentenunca segue um tratamento todo. Vocênão tem paciência (mãe 3).

Tomando como premissa a ideia popular de que a medicina está associada a"remédio" e cura, as famílias que apresentaram uma alta rotatividade de busca por profissionais possivelmente procuravam um tratamento que oferecesse soluções definitivas, ao invés de propor apenas alívio e controle dos sintomas. A perspectiva de cronicidade do transtorno, nesses casos, não estava bem compreendida ou aceita.

Com o passar dos meses ou anos, as evidências, enfim, passaram a apontar para um quadro de saúde que não regrediu magicamente. Com isso, as narrativas das mães participantes indicaram que, a despeito de seus desejos, a vida familiar sofreu alterações e precisou 
ser remodelada, a fim de que houvesse um reajustamento, ao menos parcial, às novas circunstâncias vividas.

\section{Mudanças na vida: nada voltará a ser como antes}

Quais foram, enfim, as modificações impostas no âmbito familiar pela instalação da esquizofrenia do filho?

As narrativas das mães participantes foram permeadas pelos relatos das diversas transformações que a assunção do transtorno mental trouxe para o membro acometido, para ela própria e para toda a família: "Atrapalhou toda a vida dele. E a minha também"(mãe 4).

Entre as alterações referidas, a queda do padrão socioeconômico da família foi a mais enfatizada. Os relatos mostraram que as despesas aumentaram com a necessidade de aquisição das medicações e, nos casos em que o filho já trabalhava, com a nova situação de se ter um membro a menos contribuindo para a renda familiar. Somou-se a esse quadro a necessidade de afastamento de algumas mães da própria ocupação profissional, uma vez que a atenção ao filho passou a exigir dedicação integral.

Além da impossibilidade de trabalhar, as mães relataram a diminuição ou extinção das atividades de lazer. Diante dessa condição adversa imposta à própria vida, os relatos demonstraram um sentimento de terem tido sua liberdade confiscada: "Eu tenho que ficar assim, 24 horas pra ele. Saber o que tá acontecendo. Então éisso. Minha vidaéisso. Se resumiu a ele" (mãe 7).

Sob a intensa regressão do comportamento e do estado mental desencadeada pela esquizofrenia, o alcance da autonomia e individuação do filho tornou-se drasticamente comprometido, e os laços de dependência afetiva extrema em relação a seus pais se intensificaram. Com isso, as participantes relataram ter percebido a necessidade de reformular os seus próprios planos para o futuro, uma vez que o filho acometido dependeria da família por um tempo maior do que o esperado. Aos poucos foi tomando consistência a percepção incômoda de que a função materna poderia ser requerida indefinidamente. Questionamentos acerca de quem cuidaria do filho quando estivessem impossi- passaram a ser parte integrante de suas vidas, de acordo com a narrativa da maioria das participantes.

Diante de tantas transformações no funcionamento familiar, a maioria das mães verbalizou que, com o aparecimento do transtorno mental do filho, algumas relações intra e extrafamiliares fragilizaram-se ou mesmo ruíram:

Eu acho que mudou... até na relação com meu marido, praticamente a genteéseparado, né? Sóvive junto. Acho que é por causa desse problema mesmo, né? Porque apresenta um problema, vocênão tem solução. Aí, com sete filhos, cada um tem um problema, então desequilibrou a família toda, né? ... não tem aquele negócio de 'vamos lutar juntos... (mãe 10).

Uma vizinha lá, ela entra quando ele sai na rua (mãe 4).

Ainda que a maior parte das histórias tenha apontado para o sentido do dilaceramento dos laços familiares e dos vínculos sociais, o oposto também foi mencionado. Ainda que em menor escala, algumas verbalizações abordaram o aumento da união familiar ou o fortalecimento de alguns vínculos específicos a partir da instalação do transtorno esquizofrênico no seio familiar: "Só o pai dela que não acreditava muito, achava até talvez fosse até uma falsidade aquilo lá. Então eu e os irmãos dela, a irmã casada, o solteiro mais velho, a família se uniu mais. Todos pegamos pra ajudar" (mãe 8).

Por fim, na maioria das narrativas produzidas, as participantes referiram que a convivência com o transtorno mental do filho acarretou também transformações em seus valores e crenças: mudança de religião, priorização do viver bem consigo mesma ao invés da valorização do acúmulo de bens materiais, deslocamento da preocupação para viver o presente em detrimento do foco no futuro, além de maior valorização da família e dos amigos: "Hoje eu valorizo muito a amizade, o viver bem, aproveitar o dia" (mãe 1).

Em suma, as transformações vivenciadas na família foram amplas e variadas, englobando desde fatores objetivos, tais como a queda no padrão financeiro, a diminuição do lazer e a necessidade permanente da presença de um cuidador, até fatores subjetivos, como a angústia pela necessidade de remodelar os planos para a própria vida, as alterações nas relações familiares e nos valores. Esses achados apontam para a natureza invasiva do transtorno esquizofrênico na vida do cuida- 
dor, gerando modificações tanto na rotina diária como nos aspectos financeiro, social e emocional.

\section{Aceitação ou resignação: eu quis reconstruir esse castelo}

Coexistindo com a realidade das transformações vivenciadas, que suscitaram alterações no comportamento e no sistema de valores das participantes, algumas mães evidenciaram em seus relatos que, mesmo após anos de convívio com a esquizofrenia do filho, persistiam indícios de não aceitação da condição atual do filho:

Se alguém me dissesseque era uma doença hereditária, eujánão ia mais ter ele (mãe 6).

Eu ainda não aceito totalmente não. Pra ser sincera pra você, eu não aceito. Eu ainda quero ver meu filho bom, como... antes. Ainda tenho esse sonho (mãe 7).

A maioria das mães, no entanto, não verbalizou de maneira direta a recusa em admitir a situação, mas evidenciou-a implicitamente, por meio de uma atitude de aparente resignação diante da irreversibilidade da problemática vivenciada. Por resignação entende-se a passividade frente ao sofrimento que se instalou. Nesse caso, a mãe, dominada por uma sensação de impotência, apenas conformou-se com a situação: "Você se conforma, né? Porque aceitar você não aceita..." (mãe 3).

Das 12 mães participantes, apenas uma demonstrou uma postura de aceitação do filho tal como ele se mostrava. Por aceitação entende-se a capacidade de compreender que a realidade do filho mudou e que, consequentemente, a vida familiar precisaria ser remodelada para acolhê-lo em seus novos limites e possibilidades. Trata-se de aceitar o novo filho tal como ele é, ao invés de pensar o convívio com a doença como um tormento temporário que se deve suportar até que a homeostase anterior seja restaurada:

É como se eu tivesse feito um castelo muito grande na areia e ele puf... caiu. Aíeu quis reconstruir esse castelo, da maneira que eu pude. Porque o primeiro castelo foi feito na mente... O segundo foi real. Eu peguei fui reconstruir de novo. E não saiu perfeito igual ao primeiro, mas tá saindo... Tô levantando ele (mãe 9).

Esses dados evidenciaram que, para o conjunto das participantes deste estudo, a aceitação do fato de ter na família um portador de transtorno mental crônico é uma tarefa árdua, permanentemente em construção, que requer um lento e longo processo de depuração e elaboração psíquica. Os degraus vencidos foram conquistados geralmente depois de inúmeras vivências de frustrações acumuladas no decorrer da evolução do transtorno mental. No entanto, mesmo que permeado por algumas conquistas, o que se observou na maioria dos relatos foi o penoso itinerário percorrido rumo à aceitação da nova ordem familiar.

\section{Considerações Finais}

Este estudo colocou em evidência a trajetória de mães que tiveram seus filhos diagnosticados como portadores de sofrimento mental. Inicialmente tratava-se de uma sensação de que algo estava fora do lugar: uma angústia sem nome, que motivou a busca de respostas que Ihes permitissem traduzir o desconforto gerado pelo encontro com uma realidade insólita, tão inóspita quanto potencialmente desestruturante.

Desse modo, a necessidade de compreensão da realidade na qual se viam imersas fez com que as mães mobilizassem seus recursos adaptativos. No entanto, o início da conscientização de que se tratava de um transtorno mental veio, em maior ou menor grau, acompanhado de uma resistência tenaz à ideia, refletida no adiamento da procura por ajuda médica ou na resistência posterior ao tratamento medicamentoso. Fez-se presente o desejo de uma cura milagrosa, na intenção de recuperar a antiga homeostase familiar e negar as aflições suscitadas pela confirmação diagnóstica. Ao invés disso, a realidade implacável do transtorno mental impôs muitas alterações e restrições na rotina familiar; algumas culminaram em transformações positivas de valores e outras geraram angústias diante das quais as mães viram-se impotentes e resignadas.

A reconstrução da história da convivência com a esquizofrenia a partir das narrativas das mães participantes deste trabalho permitiu a visualização de momentos distintos, cada qual com sobrecargas objetivas e subjetivas específicas. No entanto, para a maioria das participantes, houve um aspecto que se mostrou comum em todas as fases: mesmo que, com o passar do tempo, tenha havido uma evolução no sentido da conscientização e aceitação da nova realidade familiar, os indícios de não aceitação dessa condição sempre 
estiveram presentes. Para essas mães, a dificuldade de elaboração do luto pela perda do ideal de filho sadio foi perpetuada pela eterna busca de restauração do passado. Desse modo, buscavam conforto diante do imperativo de buscar sentido para o enigma da loucura.

Os resultados obtidos com esta pesquisa demonstraram os inúmeros percalços do cuidar de um portador de esquizofrenia, corroborando a importância da continuidade do processo de abertura, nos centros de saúde mental, de espaços de acolhimento para os familiares. O tempo não se mostrou capaz de estancar as feridas abertas pela assunção da enfermidade psíquica no seio familiar. Independentemente do número de anos de convívio com essa realidade, o apoio especializado mostra-se necessário.

Conhecer as especificidades das sobrecargas e identificar as necessidades de cada familiar no momento em que chega ao serviço são pré-requisitos fundamentais para incrementar a efetividade das intervenções a serem desenvolvidas junto à clientela. A experiência de sentir-se compreendido, em sua unicidade e singularidade, pelo profissional que o acolhe é, sem dúvida, um fator essencial na aderência dos familiares às intervenções em saúde mental.

\section{Referências}

Bradley, G. M., Couchman, G. M., Perlesz, A., Nguyen, A. T., Singh, B., \& Riess, C. (2006). Multiple-family group treatment for english- and vietnamese-speaking families living with schizophrenia. Psychiatric Services, 57 (4), 521-530.

Brady, N., \& McCain, G. C. (2004). Living with schizophrenia: a family perspective. Online Journal of Issues in Nursing, 10 (1), 7. Recuperado em outubro 17, 2006, disponível em http://nursingworld.org/ojin/hirsh/topic4/tpc4_2.htm

Cheng, L.Y., \& Chan, S. (2005). Psychoeducation program for chinese family carers of members with schizophrenia. Western Journal of Nursing Research, 27 (5), 583-599.
Foldemo, A., Gullberg, M., Ek, A. C., \& Bogren, L. (2005). Quality of life and burden in parents of outpatients with schizophrenia. Social Psychiatry Psychiatric Epidemiology, 40 (2), 133-138.

Gutierrez-Maldonado, J., Caqueo-Urizar, A., \& Kavanagh, D. J. (2005). Burden of care and general health in families of patients with schizophrenia. Social Psychiatry Psychiatric Epidemiology, 40 (11), 899-904.

Koukia, E., \& Madianos, M. G. (2005). Is psychosocial rehabilitation of schizophrenic patients preventing family burden? A comparative study. Journal of Psychiatric and Mental Health Nursing, 12 (4), 415-422.

Laidlaw, T. M., Coverdale, J. H., Falloon, I. R., \& Kydd R. R. (2002). Caregivers' stresses when living together or apart from patients with chronic schizophrenia. Community Mental Health Journal, 38 (4), 303-310.

Minayo, M. C. S. (2000). O desafio do conhecimento: pesquisa qualitativa em saúde (7a.ed.). São Paulo: Hucitec-Abrasco.

Moller-Leimkuhler, A. M. (2005). Burden of relatives and predictors of burden. Baseline results from the Munich 5-year-follow-up study on relatives of first hospitalized patients with schizophrenia or depression. European Archives of Psychiatry and Clinical Neuroscience, 255 (4), 223-231.

Pollio, D. E., North, C. S., Reid, D. L., Miletic, M. M., \& McClendon J. R. (2006). Living with severe mental illness: what families and friends must know: evaluation of a one-day psychoeducation workshop. Social Work, 51 (1), 31-38.

Rosenfarb, I. S., Bellack, A. S., \& Aziz N. (2006). A sociocultural stress, appraisal, and coping model of subjective burden and family attitudes toward patients with schizophrenia. Journal of Abnormal Psychology, 115 (1),157-165.

Saunders, J. C. (2003). Families living with severe mental illness: a literature review. Issues in Mental Health Nursing, 24 (2), 175-198.

Saunders, J. C., \& Byrne, M. M. (2002). A thematic analysis of families living with schizophrenia. Archives of Psychiatric Nursing, 16 (5), 217-223.

Teschinsky, U. (2000). Living with schizophrenia: the family illness experience. Issues in Mental Health Nursing, 21 (4), 387-396.

Recebido em: 8/2/2007

Aprovado em: 11/3/2008 